\title{
Novel biomarker genes which distinguish between smokers and chronic obstructive pulmonary disease patients with machine learning approach
}

Kazushi Matsumura* (1) and Shigeaki Ito

\begin{abstract}
Background: Chronic obstructive pulmonary disease (COPD) is combination of progressive lung diseases. The diagnosis of COPD is generally based on the pulmonary function testing, however, difficulties underlie in prognosis of smokers or early stage of COPD patients due to the complexity and heterogeneity of the pathogenesis. Computational analyses of omics technologies are expected as one of the solutions to resolve such complexities.

Methods: We obtained transcriptomic data by in vitro testing with exposures of human bronchial epithelial cells to the inducers for early events of COPD to identify the potential descriptive marker genes. With the identified genes, the machine learning technique was employed with the publicly available transcriptome data obtained from the lung specimens of COPD and non-COPD patients to develop the model that can reflect the risk continuum across smoking and COPD.

Results: The expression levels of 15 genes were commonly altered among in vitro tissues exposed to known inducible factors for earlier events of COPD (exposure to cigarette smoke, DNA damage, oxidative stress, and inflammation), and 10 of these genes and their corresponding proteins have not previously reported as COPD biomarkers. Although these genes were able to predict each group with 65\% accuracy, the accuracy with which they were able to discriminate COPD subjects from smokers was only $29 \%$.

Furthermore, logistic regression enabled the conversion of gene expression levels to a numerical index, which we named the "potential risk factor (PRF)" index. The highest significant index value was recorded in COPD subjects (0.56 at the median), followed by smokers (0.30) and non-smokers (0.02). In vitro tissues exposed to cigarette smoke displayed dose-dependent increases of PRF, suggesting its utility for prospective risk estimation of tobacco products.

Conclusions: Our experimental-based transcriptomic analysis identified novel genes associated with COPD, and the 15 genes could distinguish smokers and COPD subjects from non-smokers via machine-learning classification with remarkable accuracy. We also suggested a PRF index that can quantitatively reflect the risk continuum across smoking and COPD pathogenesis, and we believe it will provide an improved understanding of smoking effects and new insights into COPD.
\end{abstract}

Keywords: Gene expression, Cigarette smoke, Chronic obstructive pulmonary disease, Random forest, Classifier, Logistic regression, Computational scoring

\footnotetext{
* Correspondence: kazushi.matsumura@jt.com

Scientific Product Assessment Center, R\&D Group, Japan Tobacco Inc., 6-2

Umegaoka, Aoba-ku, Yokohama, Kanagawa 227-8512, Japan
}

(c) The Author(s). 2020 Open Access This article is distributed under the terms of the Creative Commons Attribution 4.0 International License (http://creativecommons.org/licenses/by/4.0/), which permits unrestricted use, distribution, and reproduction in any medium, provided you give appropriate credit to the original author(s) and the source, provide a link to the Creative Commons license, and indicate if changes were made. The Creative Commons Public Domain Dedication waiver (http://creativecommons.org/publicdomain/zero/1.0/) applies to the data made available in this article, unless otherwise stated. 


\section{Background}

Chronic obstructive pulmonary disease (COPD), a disorder characterized by reduced maximum expiratory flow and slow forced emptying of the lungs, is a common, costly, and preventable disease that has implications for global health [1]. Although cigarette smoke (CS) is a well-known risk factor for the development of COPD, smoking-related damage manifestations, such as airway wall thickening, loss of small airways functions, and emphysematous lung destruction, vary in individual smokers [2]. These heterogeneities of smoking-related manifestations lead to difficulty in investigating the risk continuum across smoking and COPD. Moreover, various next-generation products (NGPs), including e-cigarettes and heat-not-burn tobacco products, have been recently introduced in global markets [3, 4]. These NGPs can potentially reduce the harms associated with tobacco use because of their reduced yields of toxicants, which is attributable to the generation of aerosols without combusting tobacco leaves $[5,6]$, but the effects of long-term use of these NGPs on human health remain controversial $[7,8]$ despite previous non-clinical [9-12] and clinical studies [13-15]. Epidemiological analysis could be one of the solutions to estimate the realistic risk of the use of such products, but several years would be needed to reach a conclusion. Furthermore, epidemiological studies on a productby-product basis would be difficult because new products are frequently introduced and customer choice would vary. Considering these issues together, rapid methodology for precisely predicting the potential risk of COPD is demanded to estimate the realistic impact of NGPs in comparison with combustible cigarettes.

Alternatives to animal testing have been introduced recently based on the principle of 3Rs: reduction, refinement, and replacement [16]. They have been also expected as rapid and precise risk assessment tools because of their high resemblance to in vivo situations [17]. In terms of investigating the effects of airborne materials such as CS, a three-dimensional (3D) cultured airway epithelial cell model that functionally differentiates through an air-liquid interface (ALI) culture is more representative, exhibiting a pseudostratified columnar epithelial structure with beating cilia as observed in the human airway $[18,19]$. Our group also applied these in vitro alternative testing approaches to the investigation of biological responses to or prediction of the risks of acute or subchronic inhalation toxicity of CS [20-22]. In addition, the National Academy of Sciences [23] proposed a paradigm shift in toxicology from current animal-based testing toward the application of emerging technologies, including "-omics" technologies. This new paradigm would provide greater mechanistic insight into the mechanism by which many compounds affect human health [24]; therefore, omics technologies have also improved our understanding of the complex effects of CS [25-27]. Furthermore, these large-scale datasets may be well suited for computational methodology to develop risk prediction models [28]. However, the development of computational methodologies that can quantitatively assess human disease risk remains challenging issues.

The objective of the present study was to further understand of smoking effects and COPD pathogenesis. Among the existing omics technologies, we believe that the transcriptomic approach is one of the powerful tools because of the high quality of the data and availability of public available databases, such as ArrayExpress (https://www.ebi.ac. uk/arrayexpress/) and the GEO database (https://www.ncbi. nlm.nih.gov/geo/). Therefore, we first obtained the global transcriptomic profiles of CS exposure and COPD-related biological response inducers in ALI-cultured 3D human bronchial epithelial cells. However, the precise mechanism of action of CS exposure throughout the development of COPD has been unclear. CS-mediated oxidative stress is believed to be the uppermost biological event in respiratory tissues [29], and severe oxidative stress may lead to chronic inflammation and cellular DNA damage, as observed in the tissues of patients with COPD [30-32]. Thus, we exposed a commercially available 3D human airway epithelia reconstituted culture (MucilAir ${ }^{\mathrm{TM}}$ ) to the aqueous extract (AqE) of a reference cigarette and inducers of oxidative stress, cellular DNA damage, and inflammatory response. We hypothesized that the transcriptomes of tissues exposed to CS and those exposed to test substances possess valuable information related to COPD; therefore, we identified descriptive marker genes and their potential for reflecting the risk continuum across smoking and COPD pathogenesis. In this study, we developed an effective approach for new potential marker identification and estimation of disease risk using machine-learning techniques.

\section{Methods}

\section{Test products}

The 3R4F Kentucky reference cigarette (University of Kentucky, Lexington, KY, USA) was used as the representative conventional combustible cigarette and conditioned at $22 \pm 1{ }^{\circ} \mathrm{C}$ and $60 \pm 3 \%$ relative humidity for at least $48 \mathrm{~h}$ before use.

The oxidative stress inducers sodium hypochlorite $(\mathrm{NaClO})$ and $\mathrm{t}$-butylhydroquinone (tBHQ) were purchased from Wako Pure Chemical Industries, Ltd. (Osaka, Japan) $[33,34]$. The DNA damage inducers cisplatin and bleomycin were purchased from Wako Pure Chemical Industries, Ltd. and Tokyo Chemical Industry Co., Ltd. (Tokyo, Japan) respectively $[35,36]$. Human recombinant TNF $\alpha$ and IL-1 $\beta$ were purchased from Sigma-Aldrich (St Louis, $\mathrm{MO}$, USA) and used as inflammatory response mediators.

\section{Cell culture}

MucilAir human bronchial epithelial cultures were purchased from Epithelix Sàrl (Geneva, Switzerland). The 
cultures were composed of epithelial cells from 61-yearold Caucasian male non-smoker in MucilAir ${ }^{\mathrm{rm}}$ (batch number: MD053701). The MucilAir ${ }^{\mathrm{Tm}}$ tissues, cultured in 24-well-sized Transwell inserts (Corning, Corning, NY, USA), were placed into 24-well plates (Corning) with $700 \mu \mathrm{L}$ of MucilAir $^{\text {Twx }}$ culture medium (Epithelix Sàrl) upon arrival. The tissues were incubated at $37^{\circ} \mathrm{C}$ in a $5 \%$ $\mathrm{CO}_{2}$ atmosphere for more than 10 days for acclimation before starting exposure [37]. The medium was changed every $2-3$ days.

\section{Preparation of the AqE of cigarette smoke}

The ISO Intense smoking regimen (ISO 20778: a 55-mL bell-shaped puff taken over $2 \mathrm{~s}$, repeated every $30 \mathrm{~s}$ with blocking of filter ventilation [38]) was used for smoking 3R4F cigarettes. The AqE was prepared by bubbling the mainstream aerosol generated from 3R4F cigarettes through PneumaCult-ALI without the supplements (StemCell Technologies, Vancouver, BC, USA). Two 3R4F cigarettes were smoked in one smoking cycle to a butt length of $35 \mathrm{~mm}$ with RM20H (Borgwaldt, Hamburg, Germany), and approximately 2.0 cigarettes of 3R4F smoke were bubbled into $15 \mathrm{~mL}$ of ice-cold PneumaCult-ALI without the supplements. The supplement of PneumaCult-ALI medium was added immediately before mixing with MucilAir ${ }^{\text {Tx }}$ culture medium in accordance with the manufacturer's instructions. The AqE was diluted with MucilAir ${ }^{\text {rm }}$ culture medium to concentrations of $0.5,1.0$, and 2.0 cigarettes $/ \mathrm{L}$.

\section{Experimental design of the exposure studies}

The exposure studies were performed using each test substance and the AqE of 3R4F smoke. MucilAir ${ }^{\mathrm{Th}}$ tissue was exposed to each test substance for 4 or $24 \mathrm{~h}$ at the following concentrations: 8 and $16 \mu \mathrm{M}$ (cisplatin), 50 and $100 \mu \mathrm{g} / \mathrm{mL}$ (bleomycin), 0.7 and $1.4 \mathrm{mM}(\mathrm{NaClO})$, 20 and $40 \mu \mathrm{M}$ (tBHQ), 20 and $40 \mathrm{ng} / \mathrm{mL}$ (TNFo), and 20 and $40 \mathrm{ng} / \mathrm{mL}$ (IL-1ß). MucilAir ${ }^{\mathrm{Tm}}$ tissue was exposed to the AqE of 3R4F smoke for 4 and $24 \mathrm{~h}$ at $0.5,1.0$ and 2.0 cigarettes/L. Non-treated MucilAir ${ }^{\text {tw }}$ tissue was used as a control.

\section{Transcriptomic analysis using mRNA extracted from MucilAir tissues}

Total RNA was isolated from three tissue cultures at each time point using RNeasy (Qiagen, Hilden, Germany). The RNA quality of the samples was rated according to the RNA integrity number using an Agilent 2100 Bioanalyzer (Agilent Technologies, Santa Clara, CA, USA). Microarray analysis was conducted by Takara Bio, Inc. (Shiga, Japan) using Human Genome U133 Plus 2.0 arrays (Affymetrix, Santa Clara, CA, USA). Raw data were summarized using the GC-Robust Multiarray Average in GeneSpring Version 14.9.1 (Agilent Technologies). Data with a normalized intensity value below the 20th percentile and coefficient of variation $\geq 50 \%$ were filtered out. The filtered list was analyzed using a moderated $t$-test, and multiple testing correction of the $t$-test $p$-values was performed using the Benjamini-Hochberg FDR [39] to detect significant differences at an FDR-corrected $p<0.05$ between the exposure groups and the controls. These normalization processes were separately performed for both the AqE- and test substance-exposed groups to remove genes that exhibited high coefficients of variation. Genes exhibiting significant changes (FDR-corrected $p<0.05$ and |fold change $\mid>1.5$ in the AqE-exposed group and FDR-corrected $p<0.05$ in the test substance-exposed groups) were defined as DEGs. Hierarchical clusters and Spearman's rank correlation heatmap were generated using GeneSpring Version 14.9.1. Transcriptomic data are available in ArrayExpress at accession number E-MTAB-7992.

\section{Identification of descriptive genes from in vitro exposure study}

To identify the descriptive genes related to COPD, we analyzed the transcriptomic data from the in vitro exposure studies as follows: (1) To identify the CS-inducible genes, we analyzed the gene expression profiles of MucilAir ${ }^{\text {rm }}$ exposed to the AqE from 3R4F smoke for $4 \mathrm{~h}$ at three different concentrations $(0.5,1.0$, and 2.0 cigarettes $/ \mathrm{L})$. We compared upregulated and downregulated genes separately, and identified 25 commonly upregulated DEGs and 25 commonly downregulated DEGs (|fold change $\mid>1.5$, false discovery rate $[\mathrm{FDR}]$-corrected $p<0.05)$ from the Venn diagrams. (2) To identify the genes associated with COPDrelated biological processes, we compared the gene expression profiles of each inducer. We extracted DEGs in each test substance (cisplatin, bleomycin, $\mathrm{NaClO}, \mathrm{tBHQ}, \mathrm{TNF} \alpha$, and IL-1ß)) at each dose (low and high) and at each timepoint ( 4 or $24 \mathrm{~h}$ ), and identified common DEGs between 4 and $24 \mathrm{~h}$ exposure at the same dose for each test substance (time-independently perturbed DEGs). Subsequently, we integrated all the time-independently perturbed DEGs in each test substance, and investigated the gene expression profile using hierarchical clustering analysis. Finally, we extracted the dose-independently perturbed DEGs. (3) We compared the up- and downregulated DEGs identified in steps (1) and (2) in a Venn diagram, and ultimately identified 15 descriptive genes. Figure 2 is a graphical summary of the results.

\section{Data processing and classification analysis of public microarray datasets}

Three previously published datasets for bronchia (E-MTAB1690) and small airways (E-GEOD-20257 and E-GEOD8545) were obtained from EMBL ArrayExpress. Raw data were summarized using GC-Robust Multiarray Average in GeneSpring Version 14.9.1. The summary of sample information is shown in Table 1 . The platform for all microarray 
Table 1 Overall summary of the publicly available datasets

\begin{tabular}{lllll}
\hline Study name & Study samples & Age & Sex & Sample type \\
\hline E-MTAB-1690 & 14 NS, 27 SMK, and 21 COPD & $51.9 \pm 8.69$ & 53 male, 9 female & Respiratory tract \\
E-GEOD-20257 & 36 NS, 43 SMK, and 9 COPD & $42.8 \pm 10.9$ & 61 male, 27 female & Small airway \\
E-GEOD-8545 & 18 NS, 18 SMK, and 18 COPD & $45.7 \pm 7.18$ & 41 male, 13 female & Small airway \\
\hline
\end{tabular}

NS non-smokers, SMK smokers, COPD COPD subjects

data was Human Genome U133 Plus 2.0 Array, which we also used. These datasets included 68 non-smokers, 88 smokers, and 48 COPD subjects. These subjects were used to calculate the multi-classification accuracy using the identified genes with the RF algorithm and develop the computable model using logistic regression analysis. Multiclassification analysis using the RF algorithm were performed in the R 3.5.2 statistic environment with "caret" packages [40]. The accuracy was calculated using RF with 5fold cross-validation, repeated on 100 times independently. One-way ANOVA followed by Tukey's honest significant difference post-hoc test was performed to compare significant differences $(p<0.05)$ between groups using $\mathrm{R}$ software with "multcomp" packages [41].

\section{Individual COPD risk score prediction modeling}

Normalized expression values of samples were used to calculate the individual COPD potential risk score, named the PRF index, as follows:

Stepwise logistic regression was performed in the R statistical environment to extract the characteristic genes of smokers and COPD subjects. We then developed a prediction model with these genes using logistic regression. The equations for estimating probabilities of smoker $\left(P_{S M K}\right)$ and COPD $\left(P_{C O P D}\right)$ were as follows:

$$
\begin{aligned}
& \operatorname{logit}\left(p_{S M K}\right)=\ln \left(\frac{p_{S M K}}{1-p_{S M K}}\right)=C_{N S \mid S M K}+\beta_{1} m_{1}+\beta_{2} m_{2}+\cdots+\beta_{i} m_{i} \\
& \operatorname{logit}\left(p_{C O P D}\right)=\ln \left(\frac{p_{C O P D}}{1-p_{C O P D}}\right)=C_{S M K \mid C O P D}+\gamma_{1} n_{1}+\gamma_{2} n_{2}+\cdots+\gamma_{j} n_{j}
\end{aligned}
$$

where $C_{N S \mid S M K}$ and $C_{S M K \mid C O P D}$ denote the intercepts of each prediction model with the genes selected by comparing non-smokers to smokers and smokers to COPD subjects, respectively, $m_{i}$ or $n_{j}$ is the normalized expression value of the $i^{\text {th }}$ or $j^{\text {th }}$ gene, respectively, and $\beta_{i}$ or $\gamma_{i}$ denote the regression coefficient of the $i^{\text {th }}$ or $j^{\text {th }}$ gene, respectively. The probabilities $P_{s m k}$ and $P_{C O P D}$ were then used to compute the PRF index as follows:

$$
\mathrm{PRF}=\frac{p_{S M K} \times p_{C O P D}}{1-\left(p_{S M K} \times p_{C O P D}\right)}
$$

\section{Statistical analysis}

Tukey-Kramer multiple comparison analysis was conducted using JMP ver. 14.2.0 (SAS Institute, Cary, NC,
USA) to compare significant differences $(p<0.05)$ between groups.

\section{Results}

Differential analysis of the gene expression profiles related to the AqE of 3R4F smoke and stress inducers We analyzed the gene expression profiles of MucilAir ${ }^{\mathrm{ma}}$ exposed to the AqE of 3R4F smoke for $4 \mathrm{~h}$ at three different concentrations $(0.5,1.0$, and 2.0 cigarettes/L) and identified 50 dose-independently up- and downregulated differentially expressed genes (DEGs) (|fold change $\mid>$ 1.5, false discover rate [FDR]-corrected $p<0.05$ ) (Fig. 1a). We also obtained the gene expression profile for each inducer. We extracted time-independently perturbed DEGs, and these DEGs were subjected to hierarchical clustering analysis to identify dose-independently perturbed DEGs (Fig. 1b). The analysis revealed concentrated gene clusters containing highly up- and downregulated genes. Consequently, we merged DEGs in the AqE of 3R4F smoke and from the stress inducers, and identified 15 genes commonly up- or downregulated by the AqE of 3R4F smoke and inducers (Fig. 1c). The process of gene identification is summarized in Fig. 2, and these genes and their known functions and confirmation of their association with COPD or lung function via literature reviews using PubMed are summarized in Table 2.

\section{Predictive performance of smoking and COPD status with identified genes}

The expression levels of the 15 identified genes were compared using publicly available microarray datasets of nonsmokers, smokers, and COPD subjects (Fig. 3). Compared with the findings in non-smokers, the expression levels of ADM, AREG, CXCR4, CYP1B1, PHLDA1, SLC7A11, TXNIP, and WNT5A were significantly different in COPD subjects. In addition, compared with the findings in smokers, the expression levels of AREG, CXCR4, and DUSP6 were different in COPD subjects. We then predicted the accuracy of classification of smokers and COPD subjects using these 15 genes with the random forest (RF) classification algorithm. The 5-fold, 100 times repeated cross-validation accuracy with the identified genes outperformed that for genes described by Bosse [42] based on sensitivity and specificity values (Table 3 ). 


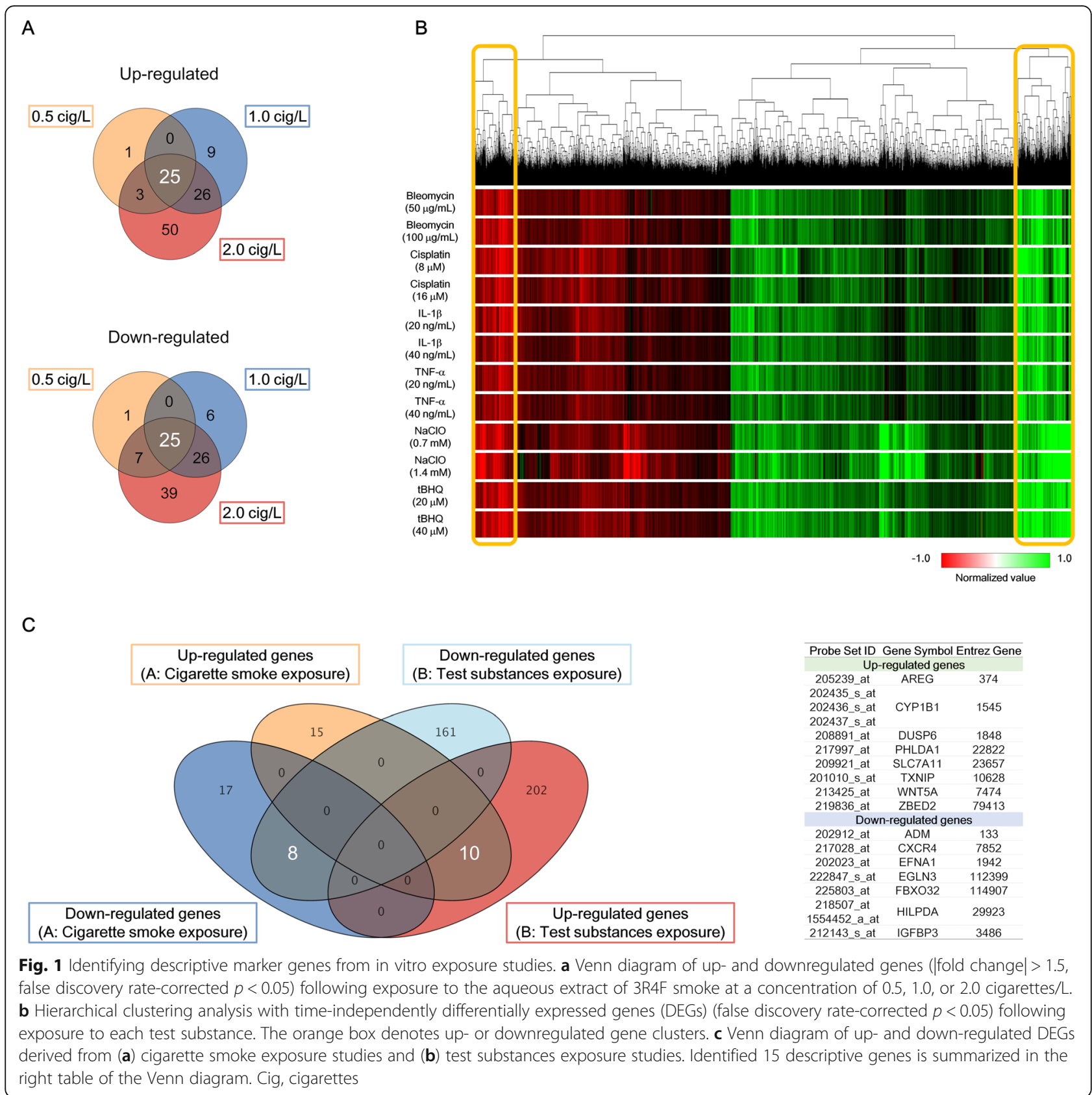

\section{Computable scoring method of potential COPD risk}

To investigate the utility of the identified genes for assessing the potential risk of COPD, we compared the potential risk factor (PRF) indices of non-smokers, smokers, and COPD subjects. Because of the similar gene expression pattern between smokers and COPD subjects, a stepwise logistic regression model was applied to extract the characteristic genes of smokers and COPD subjects. We finally identified 11 genes (ADM, AREG, CXCR4, EFNA1, EGLN3, FBXO32, HILPDA, IGFBP3, SLC7A11, TXNIP, and WNT5A) as potential descriptive marker genes for smokers and 4 genes
(AREG, DUSP6, EFNA1, and TXNIP) as potential descriptive marker genes for COPD subjects. We then calculated the logistic regression equation using the 11 and 4 genes, and the calculated parameters are summarized in Table 4. We then calculated the respective PRF indices of non-smokers, smokers, and COPD subjects to verify the validity. As expected, the highest PRF index was recorded in COPD subjects ( 0.56 at the median), followed by smokers (0.30) and non-smokers (0.02) (Fig. 4a). We also analyzed the correlations between the PRF index and both pack-years and age (Fig. 4b), and found that there was little correlation 


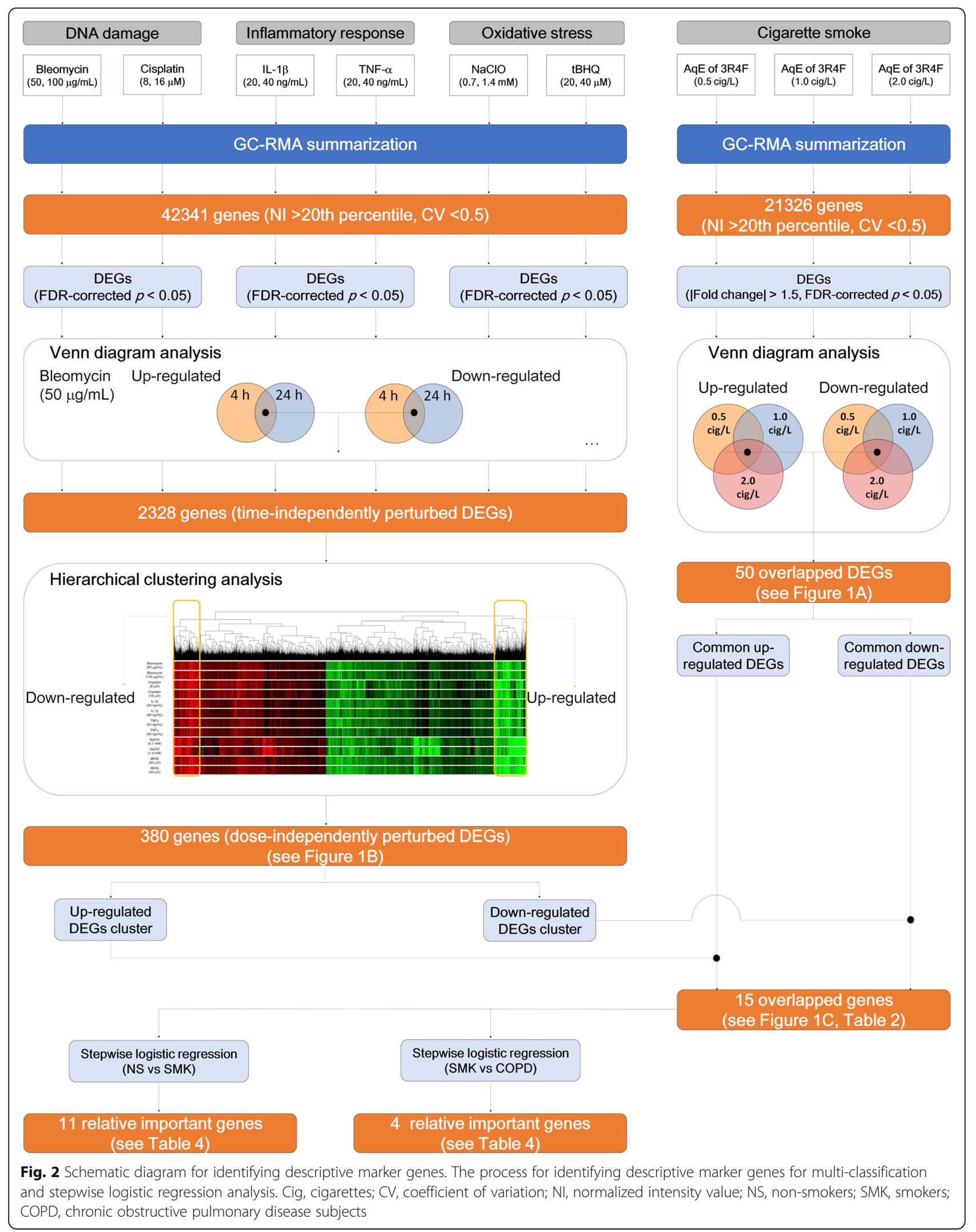


Table 2 Known function and association with chronic obstructive pulmonary disease (COPD) for identified genes

\begin{tabular}{|c|c|c|}
\hline Gene & Known function of the gene product & References (PMIDs) \\
\hline \multicolumn{3}{|c|}{ Upregulated genes } \\
\hline AREG & $\begin{array}{l}\text { Member of the EGF family, which interacts with the EGF/TGF-alpha } \\
\text { receptor to promote the growth of normal epithelial cells. }\end{array}$ & Stolarczyk M, et al. (27561911), Wang J, et al. (30291869) \\
\hline CYP1B1 & $\begin{array}{l}\text { Member of the cytochrome P450 superfamily of enzymes. High } \\
\text { expression is induced by cigarette smoke exposure. }\end{array}$ & Liu C, et al. (29110844), Slowikowski BK, et al. (28858732) \\
\hline DUSP6 & $\begin{array}{l}\text { Dual-specificity protein phosphatase subfamily. It negatively } \\
\text { regulates MAPK superfamily proteins, which are associated with } \\
\text { cellular proliferation and differentiation. }\end{array}$ & - \\
\hline PHLDA1 & $\begin{array}{l}\text { Proline-histidine-rich nuclear protein that might play an important } \\
\text { role in the anti-apoptotic effects of insulin-like growth factor- } 1 \text {. }\end{array}$ & - \\
\hline SLC7A11 & $\begin{array}{l}\text { Sodium-independent, high-affinity exchange of anionic amino acids } \\
\text { with high specificity for the anionic forms of cystine and glutamate. }\end{array}$ & - \\
\hline TXNIP & $\begin{array}{l}\text { Thioredoxin-binding protein that inhibits the antioxidative function } \\
\text { of thioredoxin, resulting in the accumulation of ROS and } \\
\text { cellular stress. }\end{array}$ & - \\
\hline WNT5A & $\begin{array}{l}\text { Wnt family member } 5 \mathrm{~A} \text {, ligand for members of the frizzled family } \\
\text { of seven-transmembrane receptors. }\end{array}$ & Koopmans T, et al. (27468699), Baarsma HA, et al. (27979969) \\
\hline ZBED2 & Zinc finger BED-type containing 2. & - \\
\hline \multicolumn{3}{|c|}{ Downregulated genes } \\
\hline ADM & $\begin{array}{l}\text { Preprohormone with several functions, including vasodilation, } \\
\text { regulation of hormone secretion, promotion of angiogenesis, and } \\
\text { antimicrobial activity. }\end{array}$ & Xu P, et al. (14720432), Meng DQ, et al. (24962223) \\
\hline CXCR4 & CXC chemokine receptor specific for stromal cell-derived factor-1. & Weigold F, et al. (29566745), Karagiannis K, et al. (28804668) \\
\hline EFNA1 & $\begin{array}{l}\text { Member of the ephrin family. Its target receptors comprise the } \\
\text { protein-tyrosine kinases, and it has been implicated in mediating } \\
\text { developmental events. }\end{array}$ & - \\
\hline EGLN3 & $\begin{array}{l}\text { Hypoxia-inducible factor. Essential for the hypoxic regulation of } \\
\text { neutrophilic inflammation and it has crucial role in DNA damage } \\
\text { response. }\end{array}$ & - \\
\hline $\mathrm{FBXO32}$ & $\begin{array}{l}\text { Fbox protein that functions in phosphorylation-dependent } \\
\text { ubiquitination and subsequent proteasomal degradation. }\end{array}$ & - \\
\hline HILPDA & $\begin{array}{l}\text { Hypoxia-inducible lipid droplet-associated protein. Stimulates } \\
\text { cytokine expression and enhances cell growth and proliferation. }\end{array}$ & - \\
\hline IGFBP3 & $\begin{array}{l}\text { Insulin-like growth factor binding protein family. It prolongs the } \\
\text { half-life of IGFs and alters their interaction with cell } \\
\text { surface receptors. }\end{array}$ & - \\
\hline
\end{tabular}

The cited references describe the confirmation of the association of the selected genes with COPD or lung function, which were obtained by reviewing the literature using PubMed ((“COPD” OR "Lung Function”) AND "name of each selected gene")

between the PRF index and pack-years $(R \approx 0.17)$, and between the PRF index and age $(R \approx 0.29)$.

\section{Discussion}

In this study, we utilized a 3D cultured bronchial epithelial tissue model, which is expected to be one of the alternative models to animal testing. We conducted exposure studies using the AqE of 3R4F smoke and inducers of oxidative stress, DNA damage, and inflammatory responses because these are considered the earliest key events for chronic inflammatory lung diseases [29-32]. To identify potential descriptive marker genes, we extracted commonly up- and down-regulated genes from the transcriptomes of tissues exposed to those test substances (Fig. 2). ADM, AREG, CXCR4, CYP1B1,
DUSP6, EFNA1, EGLN3, FBXO32, HILPDA, IGFBP3, PHLDA1, SLC7A11, TXNIP, WNT5A, and ZBED2 were identified as commonly perturbed genes, and 10 of these genes, as well as their coding proteins, had not previously been identified as biomarkers for chronic inflammatory lung disease or associated with lung function (Table 2). In addition, these 15 genes were highly correlated with each other (Additional file 1: Figure S1), suggesting that they are perturbed by the same or similar mechanisms. To verify the association of these 15 genes with COPD pathology, we performed RF-based multi-classification to discriminate COPD subjects, smokers, and non-smokers using publicly available transcriptomic data (Table 1). This model with the 15 genes clarified patient status with marginally higher accuracy than known COPD-associated 


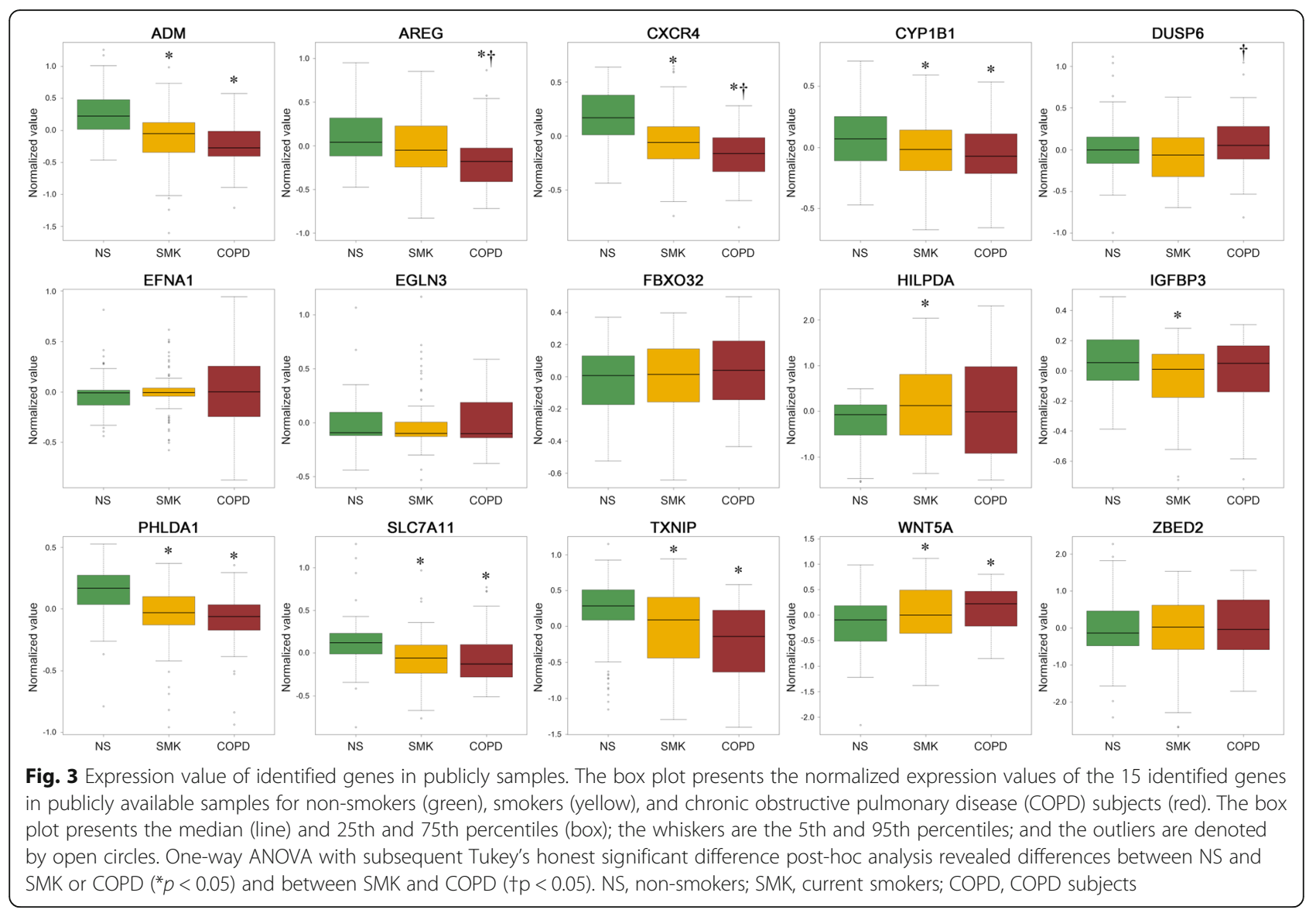

genes [42], suggesting that the 15 genes, including newly identified potential marker genes, are closely associated with COPD status. These newly identified biomarkers are related to proliferation (DUSP6 [43], EFNA1 [44], IGFBP3 [45], and PHLDA1 [46]), hypoxia (EGLN3 [47] and HILPDA [48]), redox homeostasis (SLC7A11 [49] and TXNIP [50]), and epithelial-mesenchymal transition (FBXO32 [51]) (Table 2). Among them, the expression levels of AREG, CXCR4 and DUSP6 were significantly different between non-smokers and COPD subjects, and these genes are known to be associated with EGFR signaling, which plays a key role in the pathogenesis of COPD [52]. AREG, an EGFR ligand generated by the ADAM17mediated shedding of pro-AREG proteins, stimulates the transcription of inflammatory mediators in bronchial epithelial cells [53]. Moreover, recent research illustrated that AREG-mediated IL-6 secretion is enhanced in differentiated bronchial cells from patients with COPD compared with the findings in cells from subjects without COPD $[54,55]$. CXCR4 is associated with the recruitment of lymphocytes to disease lesions [56]. The mRNA levels of the CXCR4 ligand SDF-1 are reduced in mesenchymal stem cells (MSCs) derived from bone marrow, suggesting an impairment of the migratory capacity of MSCs. MSC migration to disease lesions plays crucial roles in antiinflammatory effects and tissue repair $[57,58]$. The publicly available transcriptomic data used in this study were obtained from lung biopsies; however, downregulation of CXCR4 in COPD subjects implies attenuation of MSC recruitment, thereby eventually accelerating inflammation

Table 3 Multi-classification analysis with random forest (5-fold cross-validation repeated 100 times independently)

\begin{tabular}{|c|c|c|c|c|c|c|c|c|c|c|c|c|}
\hline \multirow{2}{*}{$\begin{array}{l}\text { Gene set } \\
\text { Pred./Truth }\end{array}$} & \multicolumn{4}{|c|}{ Original } & \multicolumn{4}{|c|}{ Published } & \multicolumn{4}{|c|}{ Extended } \\
\hline & NS & SMK & COPD & True rate & NS & SMK & COPD & True rate & NS & SMK & COPD & True rate \\
\hline NS & 25.5 & 5.8 & 1.0 & 0.77 & 16.1 & 10.2 & 4.2 & 0.48 & 19.7 & 8.8 & 2.4 & 0.59 \\
\hline SMK & 7.2 & 32.6 & 15.8 & 0.76 & 15.0 & 25.9 & 15.0 & 0.60 & 13.0 & 30.4 & 15.0 & 0.71 \\
\hline COPD & 0.6 & 4.8 & 6.7 & 0.29 & 2.2 & 7.0 & 4.3 & 0.18 & 0.6 & 4.0 & 6.2 & 0.26 \\
\hline
\end{tabular}

Classification analysis with random forest was performed using the identified 15 genes (Original) and previously published genes, including genes cited in $>10$ (Published) or $>6$ publications (Extended)

NS non-smokers, SMK smokers, COPD COPD subjects 
Table 4 The parameters calculated via stepwise logistic regression analysis

\begin{tabular}{lllll}
\hline & Estimate & Std. Error & Z value & $\operatorname{Pr}(>|Z|)$ \\
\hline (Intercept) NS|SMK & 1.6715 & 0.4229 & 3.953 & $7.73 \mathrm{E}-05$ \\
ADM & -2.2568 & 1.0247 & -2.202 & 0.027641 \\
AREG & 2.0152 & 1.0407 & 1.936 & 0.052820 \\
CXCR4 & -3.1177 & 1.4308 & -2.179 & 0.029336 \\
EFNA1 & 3.7889 & 1.9572 & 1.936 & 0.052882 \\
EGLN3 & -4.0571 & 1.7627 & -2.302 & 0.021357 \\
FBXO32 & -3.8824 & 2.4113 & -1.610 & 0.107376 \\
HILPDA & 3.2193 & 0.8100 & 3.974 & $7.06 \mathrm{E}-05$ \\
IGFBP3 & -8.2992 & 2.3747 & -3.495 & 0.000474 \\
SLC7A11 & -3.5355 & 1.2516 & -2.825 & 0.004730 \\
TXNIP & -5.6745 & 1.4851 & -3.281 & $1.33 \mathrm{E}-04$ \\
WNT5A & 2.7391 & 0.8231 & 3.328 & $8.75 \mathrm{E}-04$ \\
(Intercept) SMK|COPD & -0.8555 & 0.2144 & -3.990 & $6.61 \mathrm{E}-05$ \\
AREG & -1.3039 & 0.7058 & -1.847 & 0.06469 \\
DUSP6 & 1.4688 & 0.6254 & 2.349 & 0.01885 \\
EFNA1 & 2.3861 & 0.9058 & 2.634 & 0.00843 \\
TXNIP & -0.8847 & 0.5167 & -1.712 & $8.69 \mathrm{E}-02$ \\
\hline
\end{tabular}

(A)

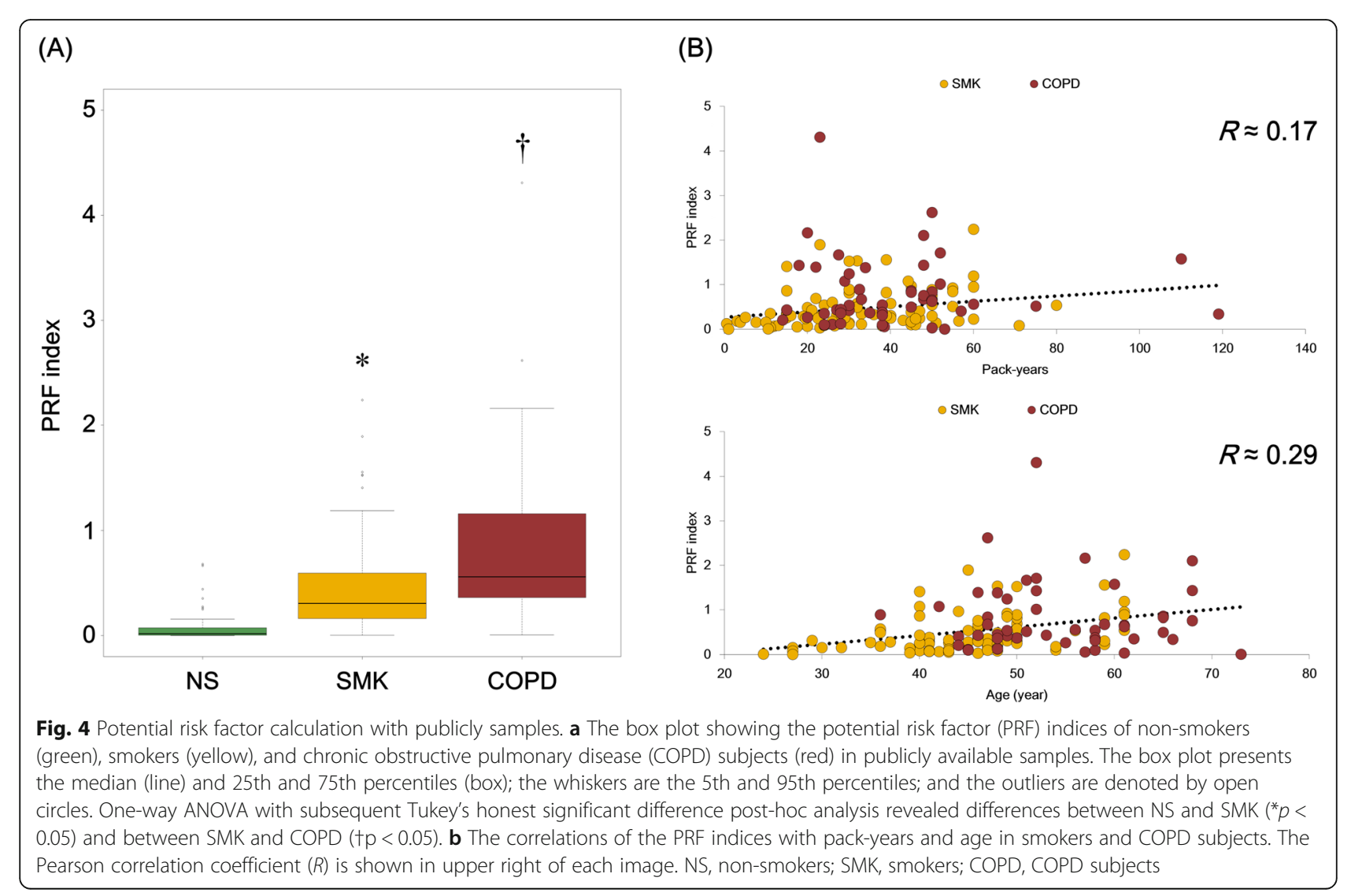

and tissue destruction. Although the direct relationship between DUSP6 and COPD has not yet been reported, several advanced studies demonstrated that activation of EGFR induces DUSP6, which regulates EGFR signaling via specific ERK1/2 inhibition [59]. Therefore, the observation of DUSP6 upregulation in COPD subjects in this study implies constitutive activation of the EGFR signaling pathway. Taken together, these three genes extracted from the transcriptome of in vitro tissues may be associated with COPD pathogenesis via the EGFR signaling pathway, and they are expected as novel markers of COPD.

Although the 15 genes were able to predict nonsmokers, smokers, and COPD subjects with high accuracy, the result clearly revealed that it is difficult to discriminate COPD subjects from smokers (Table 3). Therefore, we provide the PRF index model based on a logistic regression method to distinguish COPD subjects from smokers. This approach enabled the conversion of gene expression levels to a numeral index named the PRF index (see the formula in the Materials and Methods section). Logistic regression is used frequently in clinical trials to calculate the odds ratio when the risk ratio cannot be obtained directly [60]. The PRF index is also based on the concept of odds ratios, which indirectly estimate the risk ratio of CS exposure. Because the gene expression profiles of smokes and COPD subjects were similar, we first performed 
stepwise elimination of the 15 extracted genes to identify important variables. We selected 11 genes as important for distinguishing non-smokers from smokers, and 4 genes for distinguishing smokers from COPD subjects. Interestingly, 3 out of 4 genes for distinguishing smokers from COPD subjects (AREG, EFNA1, and TXNIP) were also marker genes for distinguishing non-smokers from smokers (Table 4). AREG was considered to be associated with EGFR signaling pathway activation as described. EFNA1 encodes a member of the ephrin family, ephrin A1. Advanced studies suggest that these proteins play an important role in inflammation through NF- $\mathrm{kB}$ signal activation [61]. Thioredoxin-interacting protein (TXNIP) reduces the anti-oxidative function of thioredoxin by binding to its redox-active cysteine residues $[62,63]$. The expression level of EFNA1 increased in smokers compared with non-smokers, and was higher in COPD subjects than in smokers (Fig. 3). On the other hand, the expression level of TXNIP decreased in smokers compared with nonsmokers, and was lower in COPD subjects than in smokers. These data suggest that those gene expression levels could provide an important means of distinguishing between smokers and COPD subjects. The PRF index was then calculated using the normalized expression values of the selected genes, the estimated intercept, and the regression coefficient of each gene. The PRF indices of smokers and COPD subjects were significantly different from that of non-smokers (Fig. 4a). Because the ages and pack-years differed significantly between the smokers and COPD subjects (Additional file 2: Figure S2A), and were moderately correlated (Additional file 2: Figure S2B), we analyzed the correlations of the PRF indices and the expression values of the 15 identified genes with age and packyears. AREG and TXNIP exhibited weak correlations with both pack-years (Additional file 3: Figure S3) and age (Additional file 4: Figure S4). However, the other genes exhibited little correlation, and notably, there were very weak correlations between the PRF indices and those factors. This suggests that a combination of several genes could appropriately reflect the risk continuum across smoking and COPD pathogenesis, and also, each individual genes used in the PRF index model may provide further understanding of smoking effects and new insights into COPD.

Although the PRF index does not reflect future COPD risk, and is incapable of diagnosing COPD severity in individuals, the model may have a potential to compare the toxicity of various tobacco products in in vitro study based on the COPD-related biological responses. We also calculated the PRF index using MucilAir ${ }^{\text {Tnx }}$ samples exposed to the AqE of 3R4F smoke for 4 and $24 \mathrm{~h}$ (Additional file 5: Figure S5). Although dose-dependent increases of the PRF index were observed, the PRF index for the lowest concentration of the $\mathrm{AqE}$ of $3 \mathrm{R} 4 \mathrm{~F}$ smoke was less than 1.0, indicating a lower risk than observed for the air-exposed control group. Because the pathological or morphological changes in smokers or patients with COPD could be caused by habitual cigarette smoking, we must examine the variability of the PRF index in a repeated long-term CS exposure study in a future analysis to validate the PRF index using in vitro experimental datasets for prospective risk estimations. In addition, it is also a reasonable next step to calculate the PRF index in a study comparing exposure to NGP vapor and conventional combustible cigarette smoke to demonstrate the usefulness of the index for the potential assessment of the relative toxicity based on the COPD-related biological responses.

We believed our model and PRF index are useful for the discrimination of non-smokers, smokers, and COPD subjects, but there are some limitations, which must be considered further. (i) Because cigarette smoking can have acute and eventually chronic effects, the smoking status of the subjects is an important consideration with regard to the gene signature (e.g., the gene expression profiles would be different between smokers with COPD and former smokers with COPD). However, we only found a clear description of the smoking status of the subjects in the EMTAB-1690 study [64-66]. Therefore, it is possible that our model ignored the factors related to acute phase effects in the COPD subjects. (ii) Eight substances, focusing on three biological events, were used to identify COPDassociated biomarker genes. Because COPD is a complex disease, other important biological perturbations such as apoptosis and autophagy are involved. Gene expression profiles obtained in additional exposure studies using the inducers of such biological events would increase the plausibility of potential biomarker genes. (iii) We utilized microarrays to analyze gene expression profiles in this study; however, next-generation sequencing could potentially permit a more comprehensive analysis of RNA expression profiles including non-coding RNAs. As such, room for improvement of our methodology remains, but our present approach suggests that mechanism-based large-scale dataset generation combined with computational analyses is useful for biomarker identification and risk estimation using the identified biomarker genes.

\section{Conclusion}

Our results strongly suggest that the combination of large-scale datasets and computational modeling represents a powerful approach for identifying novel biomarkers to further understand the smoking effects and providing new insights into COPD. Considering that the selected genes were originally identified in an in vitro exposure study, the application of PRF scoring for prospective toxicity of combustible CS and comparisons with NGPs in a repeated long-term exposure study are conceivable next steps. 


\section{Supplementary information}

Supplementary information accompanies this paper at https://doi.org/10. 1186/s12890-020-1062-9

Additional file 1: Figure S1. Spearman's correlation coefficients analysis. Hierarchical clustering of the Spearman's correlation coefficients of the 15 identified genes. Normalized intensity values following exposure to the aqueous extract of 3R4F smoke were subjected to the analysis.

Additional file 2: Figure S2. Comparison of age and pack-years between smokers and COPD subjects. (A) The box plot showing the age and pack-years of non-smokers (NS), smokers (SMK), and COPD subjects (COPD) in publicly available datasets. The box plot presents the median (line) and 25th and 75th percentiles (box); the whiskers are the 5th and 95th percentiles. The dots beyond the whiskers represent outlying data. The histogram shows the number of subjects in each group. Tukey-Kramer multiple comparison analysis revealed differences between NS and SMK $\left({ }^{*} p<0.05\right)$ and between SMK and COPD ( $\left.t p<0.05\right)$. (2) Correlation between age and pack-years in SMK and COPD.

Additional file 3: Figure S3. Correlation analysis of gene expression value of each identified gene with pack-years. Correlation between the pack-years and the normalized intensity value of each gene with all smokers and COPD subjects. The Pearson correlation coefficient $(R)$ is shown in the upper right of each image.

Additional file 4: Figure S4. Correlation analysis of gene expression value of each identified gene with age. Correlation between the packyears and the normalized intensity value of each gene with all smokers and COPD subjects. The Pearson correlation coefficient $(R)$ is shown in the upper right of each image.

Additional file 5: Figure S5. Potential risk factor calculation with in vitro exposure study. The potential risk factor (PRF) index ratios versus control for exposure to the aqueous extract of 3R4F smoke for 4 and 24 $h$ at $0.5,1.0$, and 2.0 cigarettes/L. Each value is presented as the mean and standard deviation of three tissues. Cig: cigarettes.

\section{Abbreviations}

3D: Three-dimensional; ALI: Air-liquid interface; AqE: Aqueous extract; COPD: Chronic obstructive pulmonary disease; CS: Cigarette smoke; DEG: Differentially expressed gene; FDR: False discovery rate; MSC: Mesenchymal stem cell; NGP: Next-generation product; PRF: Potential risk factor; RF: Random forest

\section{Acknowledgments}

We are deeply grateful to Dr. Manabu Iwasaki for giving insightful comments and suggestions on current study. We are grateful to Drs. Tomoki Nishino and Hitoshi Fujimoto for helpful discussions and suggestions on this project. We thank Joe Barber Jr., PhD, from Edanz Group (www.edanzediting.com/ac) for editing a draft of this manuscript.

\section{Authors' contributions}

KM and SI developed the concept and design of the research, performed the experiments, and interpreted the results of the experiments. KM and SI wrote the manuscript and approved the final manuscript.

\section{Funding}

This research received no specific grant from any funding agency in the public, commercial, or not-for-profit sectors.

\section{Availability of data and materials}

Implementations of algorithms and mathematical methods used in the current study are all available as opensource software. Transcriptomics datasets used in current study are available in ArrayExpress at accession number E-MTAB-7992, E-MTAB-1690, E-GEOD-20257, and E-GEOD-8545.

\section{Ethics approval and consent to participate}

All procedures in the current study were performed in accordance with approval from the local research ethics committees at Japan Tobacco Inc. Datasets of healthy non-smokers, healthy current smokers, and smokers with
COPD used in the current study are all from secondary sources, where primary ethics approval had obtained for data acquisition.

\section{Consent for publication}

Not applicable.

\section{Competing interests}

The authors are employees of Japan Tobacco Inc., and they have no competing interests with respect to the research, authorship, and/or publication of this article.

Received: 31 May 2019 Accepted: 24 January 2020

Published online: 03 February 2020

\section{References}

1. Hurd S. The impact of COPD on lung health worldwide: epidemiology and incidence. Chest. 2000;117(2):1S-4S

2. Castaldi PJ, Dy J, Ross J, Chang Y, Washko GR, Curran-Everett D, Williams A, Lynch DA, Make BJ, Crapo JD, et al. Cluster analysis in the COPDGene study identifies subtypes of smokers with distinct patterns of airway disease and emphysema. Thorax. 2014;69(5):415-22.

3. Adkison SE, O'Connor RJ, Bansal-Travers M, Hyland A, Borland R, Yong HH, Cummings KM, McNeill A, Thrasher JF, Hammond D, et al. Electronic nicotine delivery systems: international tobacco control four-country survey. Am J Prev Med. 2013;44(3):207-15.

4. Agaku IT, King BA, Husten CG, Bunnell R, Ambrose BK, Hu SS, Holder-Hayes E, Day HR. Tobacco product use among adults--United States, 2012-2013. MMWR Morb Mortal Wkly Rep. 2014;63(25):542-7.

5. Murphy J, Gaca M, Lowe F, Minet E, Breheny D, Prasad K, Camacho O, Fearon IM, Liu C, Wright $C$, et al. Assessing modified risk tobacco and nicotine products: description of the scientific framework and assessment of a closed modular electronic cigarette. Regul Toxicol Pharmacol. 2017;90:342-57.

6. Peitsch MC, Polosa R, Proctor C, Hassler T, Gaca M, Hill E, Hoeng J, Hayes AW. Next-generation tobacco and nicotine products: Substantiating harmreduction and supporting tobacco regulatory science. Toxicol Res Appl. 2018;2:1-12.

7. Sussan TE, Gajghate S, Thimmulappa RK, Ma J, Kim JH, Sudini K, Consolini N, Cormier SA, Lomnicki S, Hasan F, et al. Exposure to electronic cigarettes impairs pulmonary anti-bacterial and anti-viral defenses in a mouse model. PLoS One. 2015;10(2):e0116861

8. Callahan-Lyon P. Electronic cigarettes: human health effects. Tob Control. 2014;23 Suppl 2:ii36-40

9. Munakata S, Ishimori K, Kitamura N, Ishikawa S, Takanami Y, Ito S. Oxidative stress responses in human bronchial epithelial cells exposed to cigarette smoke and vapor from tobacco- and nicotine-containing products. Regul Toxicol Pharmacol. 2018;99:122-8.

10. Ishikawa S, Matsumura K, Kitamura N, Ishimori K, Takanami Y, Ito S. Application of a direct aerosol exposure system for the assessment of biological effects of cigarette smoke and novel tobacco product vapor on human bronchial epithelial cultures. Regul Toxicol Pharmacol. 2018;96:85-93.

11. Kogel U, Schlage WK, Martin F, Xiang Y, Ansari S, Leroy P, Vanscheeuwijck P, Gebel S, Buettner A, Wyss C, et al. A 28-day rat inhalation study with an integrated molecular toxicology endpoint demonstrates reduced exposure effects for a prototypic modified risk tobacco product compared with conventional cigarettes. Food Chem Toxicol. 2014;68:204-17.

12. Oviedo A, Lebrun S, Kogel U, Ho J, Tan WT, Titz B, Leroy P, Vuillaume G, Bera M, Martin F, et al. Evaluation of the Tobacco Heating System 2.2. Part 6: 90-day OECD 413 rat inhalation study with systems toxicology endpoints demonstrates reduced exposure effects of a mentholated version compared with mentholated and non-mentholated cigarette smoke. Regul Toxicol Pharmacol. 2016;81 Suppl 2:S93-S122.

13. Yuki D, Sakaguchi C, Kikuchi A, Futamura Y. Pharmacokinetics of nicotine following the controlled use of a prototype novel tobacco vapor product. Regul Toxicol Pharmacol. 2017;87:30-5.

14. Yuki D, Takeshige $Y$, Nakaya K, Futamura $Y$. Assessment of the exposure to harmful and potentially harmful constituents in healthy Japanese smokers using a novel tobacco vapor product compared with conventional cigarettes and smoking abstinence. Regul Toxicol Pharmacol. 2018;96:127-34.

15. Martin F, Talikka M, Ivanov NV, Haziza C, Hoeng J, Peitsch MC. Evaluation of the tobacco heating system 2.2. Part 9: Application of systems 
pharmacology to identify exposure response markers in peripheral blood of smokers switching to THS2.2. Regul Toxicol Pharmacol. 2016;81 Suppl 2:S151-7.

16. Tornqvist E, Annas A, Granath B, Jalkesten E, Cotgreave I, Oberg M. Strategic focus on $3 R$ principles reveals major reductions in the use of animals in pharmaceutical toxicity testing. PLoS One. 2014;9(7):e101638.

17. McMullen PD, Andersen ME, Cholewa B, Clewell HJ 3rd, Dunnick KM, Hartman JK, Mansouri K, Minto MS, Nicolas Cl, Phillips MB, et al. Evaluating opportunities for advancing the use of alternative methods in risk assessment through the development of fit-for-purpose in vitro assays. Toxicol in Vitro. 2018;48:310-7.

18. Aufderheide M, Scheffler S, Mohle N, Halter B, Hochrainer D. Analytical in vitro approach for studying cyto- and genotoxic effects of particulate airborne material. Anal Bioanal Chem. 2011:401(10):3213-20.

19. Aufderheide M, Halter B, Mohle N, Hochrainer D. The CULTEX RFS: a comprehensive technical approach for the in vitro exposure of airway epithelial cells to the particulate matter at the air-liquid interface. Biomed Res Int. 2013;2013:734137.

20. Aufderheide M, Scheffler S, Ito S, Ishikawa S, Emura M. Ciliatoxicity in human primary bronchiolar epithelial cells after repeated exposure at the air-liquid interface with native mainstream smoke of K3R4F cigarettes with and without charcoal filter. Exp Toxicol Pathol. 2015;67(7-8):407-11.

21. Ishikawa S, Ito S. Repeated whole cigarette smoke exposure alters cell differentiation and augments secretion of inflammatory mediators in airliquid interface three-dimensional co-culture model of human bronchial tissue. Toxicol in Vitro. 2017;38:170-8.

22. Aufderheide M, Ito S, Ishikawa S, Emura M. Metaplastic phenotype in human primary bronchiolar epithelial cells after repeated exposure to native mainstream smoke at the air-liquid interface. Exp Toxicol Pathol. 2017;69(5):307-15.

23. National Research Council. Toxicity testing in the 21st century: a vision and a strategy. Washington, DC: The National Academies Press; 2007. https://doi. org/10.17226/11970.

24. Hartung T, Van Vliet E, Jaworska J, Bonilla L, Skinner N, Thomas R. Systems toxicology. ALTEX. 2012;29(2):119-28.

25. Ishikawa S, Matsumura K, Kitamura N, Takanami Y, Ito S. Multi-omics analysis: repeated exposure of a $3 \mathrm{D}$ bronchial tissue culture to whole-cigarette smoke. Toxicol in Vitro. 2019;54:251-62.

26. Iskandar AR, Martin F, Talikka M, Schlage WK, Kostadinova R, Mathis C, Hoeng J, Peitsch MC. Systems approaches evaluating the perturbation of xenobiotic metabolism in response to cigarette smoke exposure in nasal and bronchial tissues. Biomed Res Int. 2013;2013:512086.

27. Banerjee A, Haswell LE, Baxter A, Parmar A, Azzopardi D, Corke S, Thorne D, Adamson J, Mushonganono J, Gaca MD, et al. Differential gene expression using RNA sequencing profiling in a reconstituted airway epithelium exposed to conventional cigarette smoke or electronic cigarette aerosols. Appl In Vitro Toxicol. 2017;3(1):84-98.

28. Sturla SJ, Boobis AR, FitzGerald RE, Hoeng J, Kavlock RJ, Schirmer K, Whelan M, Wilks MF, Peitsch MC. Systems toxicology: from basic research to risk assessment. Chem Res Toxicol. 2014;27(3):314-29.

29. Barreiro E, Peinado VI, Galdiz JB, Ferrer E, Marin-Corral J, Sanchez F, Gea J, Barbera JA, Project EiC. Cigarette smoke-induced oxidative stress: a role in chronic obstructive pulmonary disease skeletal muscle dysfunction. Am J Respir Crit Care Med. 2010;182(4):477-88.

30. Neofytou E, Tzortzaki EG, Chatziantoniou A, Siafakas NM. DNA damage due to oxidative stress in chronic obstructive pulmonary disease (COPD). Int J Mol Sci. 2012;13(12):16853-64.

31. Asami S, Manabe H, Miyake J, Tsurudome $Y$, Hirano $T$, Yamaguchi $R$, Itoh $H$, Kasai $\mathrm{H}$. Cigarette smoking induces an increase in oxidative DNA damage, 8-hydroxydeoxyguanosine, in a central site of the human lung. Carcinogenesis. 1997:18(9):1763-6.

32. van der Vaart $\mathrm{H}$, Postma DS, Timens W, ten Hacken NH. Acute effects of cigarette smoke on inflammation and oxidative stress: a review. Thorax. 2004;59(8):713-21.

33. Hamamoto Y, Ano S, Allard B, O'Sullivan M, McGovern TK, Martin JG Montelukast reduces inhaled chlorine triggered airway hyperresponsiveness and airway inflammation in the mouse. Br J Pharmacol. 2017;174(19):3346-58.

34. Lian F, Wang XD. Enzymatic metabolites of lycopene induce Nrf2-mediated expression of phase II detoxifying/antioxidant enzymes in human bronchial epithelial cells. Int J Cancer. 2008;123(6):1262-8.

35. Liu H, Knabb JR, Spike BT, Macleod KF. Elevated poly-(ADP-ribose)polymerase activity sensitizes retinoblastoma-deficient cells to DNA damage-induced necrosis. Mol Cancer Res. 2009;7(7):1099-109.
36. Yue X. Epithelial deletion of Sulf2 exacerbates Bleomycin-induced lung injury, inflammation, and mortality. Am J Respir Cell Mol Biol. 2017;57(5):560-9.

37. Ito S, Ishimori K, Ishikawa S. Effects of repeated cigarette smoke extract exposure over one month on human bronchial epithelial organotypic culture. Toxicol Rep. 2018;5:864-70.

38. ISO 20778:2018, Cigarettes - Routine analytical cigarette smoking machine Definitions and standard conditions with an intense smoking regime. https://www.iso.org/obp/ui/\#iso:std:iso:20778:ed-1:v1:en.

39. Yoav B, Yosef H. Controlling the false discovery rate: a practical and Poweful approach to multiple testing. J R Stat Soc Ser B Methodol. 1995;57(1):289-300.

40. Kuhn M: caret: Classification and Regression Training. R package version 6.085. 2020. https://CRAN.R-project.org/package $=$ caret.

41. Hothorn $T$, Bretz F, Westfall P. Simultaneous inference in general parametric models. Biom J. 2008:50(3):346-63.

42. Bosse Y. Updates on the COPD gene list. Int J Chron Obstruct Pulmon Dis. 2012;7:607-31.

43. Ahmad MK, Abdollah NA, Shafie NH, Yusof NM, Razak SRA. Dual-specificity phosphatase 6 (DUSP6): a review of its molecular characteristics and clinical relevance in cancer. Cancer Biol Med. 2018:15(1):14-28.

44. Miao H, Wang B. Eph/ephrin signaling in epithelial development and homeostasis. Int J Biochem Cell Biol. 2009:41(4):762-70.

45. Takaoka M, Smith CE, Mashiba MK, Okawa T, Andl CD, El-Deiry WS, Nakagawa H. EGF-mediated regulation of IGFBP-3 determines esophageal epithelial cellular response to IGF-I. Am J Physiol-Gastr L. 2006;290(2):G404

46. Sakthianandeswaren A, Christie M, D'Andreti C, Tsui C, Jorissen RN, Li S, Fleming NI, Gibbs P, Lipton L, Malaterre J, et al. PHLDA1 expression marks the putative epithelial stem cells and contributes to intestinal tumorigenesis. Cancer Res. 2011;71(10):3709-19.

47. Pescador N, Cuevas Y, Naranjo S, Alcaide M, Villar D, Landazuri MO, Del Peso $\mathrm{L}$. Identification of a functional hypoxia-responsive element that regulates the expression of the egl nine homologue 3 (egln3/phd3) gene. Biochem J. 2005:390(Pt 1):189-97.

48. Mattijssen F, Georgiadi A, Andasarie T, Szalowska E, Zota A, Krones-Herzig A, Heier C, Ratman D, De Bosscher K, Qi L, et al. Hypoxia-inducible lipid droplet-associated (HILPDA) is a novel peroxisome proliferator-activated receptor (PPAR) target involved in hepatic triglyceride secretion. J Biol Chem. 2014;289(28):19279-93.

49. Conrad M, Sato $\mathrm{H}$. The oxidative stress-inducible cystine/glutamate antiporter, system $\times(c)(-)$ : cystine supplier and beyond. Amino Acids. 2012:42(1):231-46.

50. Zhou R, Tardivel A, Thorens B, Choi I, Tschopp J. Thioredoxin-interacting protein links oxidative stress to inflammasome activation. Nat Immunol. 2010;11(2):136-40

51. Sahu SK, Tiwari N, Pataskar A, Zhuang Y, Borisova M, Diken M, Strand S, Beli $P$, Tiwari VK. FBXO32 promotes microenvironment underlying epithelialmesenchymal transition via CtBP1 during tumour metastasis and brain development. Nat Commun. 2017:8(1):1523.

52. Luettich K, Talikka M, Lowe FJ, Haswell LE, Park J, Gaca MD, Hoeng J. The adverse outcome pathway for oxidative stress-mediated EGFR activation leading to decreased lung function. Appl In Vitro Toxicol. 2017:3(1):99-109.

53. Richter A, O'donnell RA, Powell RM, Sanders MW, Holgate ST, Djukanovic R, Davies DE. Autocrine ligands for the epidermal growth factor receptor mediate interleukin-8 release from bronchial epithelial cells in response to cigarette smoke. Am J Resp Cell Mol. 2002;27(1):85-90.

54. Stolarczyk M, Scholte BJ. The EGFR-ADAM17 Axis in chronic obstructive pulmonary disease and cystic fibrosis lung pathology. Mediat Inflamm. 2018; 2018:1067134.

55. Stolarczyk M, Amatngalim GD, Yu X, Veltman M, Hiemstra PS, Scholte BJ. ADAM17 and EGFR regulate IL-6 receptor and amphiregulin mRNA expression and release in cigarette smoke-exposed primary bronchial epithelial cells from patients with chronic obstructive pulmonary disease (COPD). Physiol Rep. 2016;4(16):e12878.

56. Dupin I, Allard B, Ozier A, Maurat E, Ousova O, Delbrel E, Trian T, Bui HN Dromer C, Guisset O, et al. Blood fibrocytes are recruited during acute exacerbations of chronic obstructive pulmonary disease through a CXCR4dependent pathway. J Allergy Clin Immunol. 2016;137(4):1036-42 e1037.

57. Shigemura N, Okumura M, Mizuno S, Imanishi Y, Matsuyama A, Shiono H, Nakamura T, Sawa Y. Lung tissue engineering technique with adipose stromal cells improves surgical outcome for pulmonary emphysema. Am J Respir Crit Care Med. 2006;174(11):1199-205. 
58. Rada B, Gardina P, Myers TG, Leto TL. Reactive oxygen species mediate inflammatory cytokine release and EGFR-dependent mucin secretion in airway epithelial cells exposed to Pseudomonas pyocyanin. Mucosal Immunol. 2011:4(2):158-71.

59. Phuchareon J, McCormick F, Eisele DW, Tetsu O. EGFR inhibition evokes innate drug resistance in lung cancer cells by preventing Akt activity and thus inactivating Ets-1 function. Proc Natl Acad Sci U S A. 2015; 112(29):E3855-63.

60. Zhang J, Kai FY. What's the relative risk?: a method of correcting the odds ratio in cohort studies of common outcomes. Jama. 1998;280(19):1690-1.

61. Coulthard MG, Morgan M, Woodruff TM, Arumugam TV, Taylor SM, Carpenter TC, Lackmann M, Boyd AW. Eph/Ephrin signaling in injury and inflammation. Am J Pathol. 2012;181(5):1493-503.

62. Nishiyama A, Matsui M, Iwata S, Hirota K, Masutani H, Nakamura H, Takagi Y, Sono H, Gon Y, Yodoi J. Identification of thioredoxin-binding protein-2/ vitamin D3 up-regulated protein 1 as a negative regulator of thioredoxin function and expression. J Biol Chem. 1999;274(31):21645-50.

63. Schulze PC, Yoshioka J, Takahashi T, He Z, King GL, Lee RT. Hyperglycemia promotes oxidative stress through inhibition of thioredoxin function by thioredoxin-interacting protein. J Biol Chem. 2004;279(29):30369-74.

64. Ammous Z, Hackett NR, Butler MW, Raman T, Dolgalev I, O'Connor TP, Harvey BG, Crystal RG. Variability in small airway epithelial gene expression among normal smokers. Chest. 2008;133(6):1344-53.

65. Shaykhiev R, Otaki F, Bonsu P, Dang DT, Teater M, Strulovici-Barel Y, Salit J, Harvey BG, Crystal RG. Cigarette smoking reprograms apical junctional complex molecular architecture in the human airway epithelium in vivo. Cell Mol Life Sci. 2011;68(5):877-92.

66. Van Dyck E, Nazarov PV, Muller A, Nicot N, Bosseler M, Pierson S, Van Moer $\mathrm{K}$, Palissot V, Mascaux C, Knolle U, et al. Bronchial airway gene expression in smokers with lung or head and neck cancer. Cancer Med. 2014;3(2):322-36.

\section{Publisher's Note}

Springer Nature remains neutral with regard to jurisdictional claims in published maps and institutional affiliations.

Ready to submit your research? Choose BMC and benefit from:

- fast, convenient online submission

- thorough peer review by experienced researchers in your field

- rapid publication on acceptance

- support for research data, including large and complex data types

- gold Open Access which fosters wider collaboration and increased citations

- maximum visibility for your research: over $100 \mathrm{M}$ website views per year

At $\mathrm{BMC}$, research is always in progress.

Learn more biomedcentral.com/submissions 